\title{
BLADDER CONTROL IN THE FEMALE PARAPLEGIC PATIENT
}

\author{
By A. T. Jousse, M.D., Margaret MacDonald and Megan Wynn-Jones, M.D. \\ Lyndhurst Lodge, Spinal Injuries Centre, Toronto, Canada
}

\section{INTRODUCTION}

THE mastery of the technique of emptying the paralysed bladder is the sine qua non for the enjoyment of health, the prolongation of life and for social acceptance on the part of the paraplegic patient. Failure to empty the bladder completely at regular intervals leads to urinary sepsis, first in the bladder and later in the upper urinary tract. This in time may lead to renal damage and death. The need to remain dry and free from urinary odour while achieving regular elimination from the bladder is requisite for social acceptance.

The male paraplegic is fortunate that the formation of his external genitalia is such as to render the fitting of a urinary collecting device quite simple. For the female patient no satisfactory urinal has as yet been devised. At first sight this might seem to be a disadvantage. However, the necessity of emptying the bladder at intervals, together with the need to preserve urinary continence, is so impelling for the human female that the results of bladder training leading to bladder control are better for the female paraplegic than for the male.

\section{MANAGEMENT}

The female patient who becomes paraplegic undergoes the same type of physical restoration programme as does the male. This consists of exercises designed to restore general well-being, the mastering of some form of locomotion, either brace walking or wheelchair mobility, mastery of the activities of daily living, including control of bladder and bowel.

Bladder training, as it is called, is a most important part of the programme. The success of this training depends on many factors: the type of bladder, i.e. upper motor neurone $\mathrm{E}$ (hypertonic) or lower motor neurone (atonic), as well as the bladder capacity; the co-operation and understanding of the patient, which is, to a great extent, determined by careful education of the paraplegic individual; the attitude of the patient toward her disability and toward those who are seeking to help her; the age and degree of vigour of the patient and the skill with which she masters mobility.

During and following the acute stage of paraplegia or quadriplegia, it is a common practice to drain the bladder by means of an inlying retention catheter. To minimise infection and maintain bladder capacity, frequent irrigation of the bladder is required. Clamping the catheter for several hours at a time is sometimes advocated. Intermittent catheterisation is a recommended practice in certain centres.

Cystometry is performed in order to determine the type of bladder-i.e. hypertonic or atonic and also bladder size. Freedom from acute cystitis, bladder calculi or ureteral reflux should be established before bladder training is undertaken. 


\section{Bladder Training}

The routine for bladder training is instituted once the patient has been up in a wheelchair for several hours daily and is able to get on and off the toilet unaided or with a minimum of assistance. Ideally this transfer should be effected with ease as otherwise it may precipitate incontinence. Such unaided transfer may not, of course, be possible at any time for the patient who is quadriplegic, elderly, obese or simply unwilling to try.

The next step is removal of the catheter. It is commonly removed in the morning before breakfast. If the bladder capacity is $200 \mathrm{ml}$. or more, the patient is instructed to go to the bathroom every hour and get on the toilet. An effort is then made to expel urine. For the patient with the lower motor neurone lesion (atonic bladder) it may suffice to take a deep breath and strain. This causes contraction of the abdominal muscles which are usually intact in such a patient and leads to increased intra-abdominal pressure. Urine may be expelled. If no urine escapes, the nurse may then compress the lower abdomen with her hand, when urine may be voided. The posture of the patient is important; leaning forward and grasping the ankles and straining assists some patients to expel urine. The expelled urine is collected, measured, and the amount recorded. After three or four such attempts the catheter is reinserted and the patient is allowed to rest for 24 hours.

For the patient with an upper motor neurone lesion and a hypertonic or spastic bladder, the same routine is enacted. However, the ability to increase intraabdominal pressure is limited as the abdominal muscles are commonly paralysed. If there is spasticity of the abdominal muscles, a deep breath may increase intraabdominal pressure sufficiently to expel some urine. The patient with an upper motor neurone lesion and a hypertonic bladder is more likely to void by inducing reflex contractions in the detrusor muscle. This is sometimes a direct response to the stretching of the detrusor muscle as the bladder fills, the so-called automatic bladder effect. Again, an emptying contraction of the detrusor may be initiated by applying a stimulus to the lower extremities, genitalia or buttocks such as is known at times to induce a reflex contraction of the muscles of the legs or trunk. Such a stimulus may consist of stroking the sole with a sharp object, pulling a hair or pinching the skin. Associated with the response of the skeletal muscles there may be a contraction of the detrusor muscle of the bladder. Such stimuli may require repetition at intervals in order that a succession of contractions of the detrusor muscle may occur with the expulsion of a significant amount of urine.

Whether successful or not, after several attempts over a ten-minute period, the patient desists and returns to the wheelchair. The trial is repeated one hour later. As to the lower motor neurone lesion, after three or four such attempts, the catheter is re-inserted and the patient allowed to rest from her efforts for 24 hours. The residual urine, as well as the total amount voided, is recorded.

This routine is repeated daily. Commonly no urine, or very little, is voided the first few days but gradually more and more is expelled and the residual tends to decrease in amount. The objective is, of course, to reduce the residual to zero. Occasionally this is achieved on the first try.

The size of the bladder and the amount of fluid are important factors. If the bladder is small it quickly fills to capacity and urine is expelled with consequent wetting. This is observed and recorded. Less fluid intake, or more frequent attempts at voiding may be indicated. Generally, with the mastery of bladder 
control the interval between attempts to void may be increased up to two, three, four or even five hours, while remaining dry. At night it is not unusual for a patient to sleep for six or seven hours without being incontinent. Once she learns to expel urine at will and is able to remain dry between attempts at voiding and reduces the residual urine to less than 20 per cent. of the bladder capacity, the catheter is left out.

When the residual remains high (greater than 20 per cent. of the bladder capacity) special measures may be required to promote bladder emptying. These may consist of the administration of drugs such as prostigmin, urocholine, eserine or carbachol, which promote contraction of the detrusor muscle. Again, bladder emptying may be encouraged if a gloved finger is inserted into the rectum. Frequently the bladder empties most effectively concurrently with a bowel evacuation.

If there is total retention with a spastic bladder, spasm in the vesicle sphincter must be suspected. This may be interrupted by blocking the internal pudendal nerves, using local anaesthetic. Although each nerve block lasts but an hour or two, the accumulative effect of several blocks on successive days may suffice to permit of bladder emptying.

Incontinence may occur in the patient with a small, very spastic bladder which contracts and expels urine every few minutes. Leakage occurs either around the catheter or, if the catheter is removed, directly per urethram. The use of anticholinergic drugs may suffice to decrease the sensitivity of the bladder and thus increase the effective capacity. The administration of this type of drug facilitates mastery of bladder control in certain patients.

If the spastic bladder becomes small and contracted by virtue of the prolonged use of an inlying catheter, frequently little progress is made toward mastering bladder control. Indeed if this state has persisted for months or years, the condition of the bladder may be irreversibly small and contracted and this is, of course, a sentence to permanent catheter drainage.

To assess the status of the bladder and determine whether or not the small size is reversible or irreversible, a simple procedure is carried out. It consists of the administration of a spinal anaesthetic by an anaesthetist. Cystometry before and after the anaesthetic reveals the answer. If the bladder expands under spinal anaesthesia the examiner knows that fixed contraction has not occurred. The larger size may be maintained by means of a surgical rhyzotomy of the appropriate sacral roots, or by local infiltration of these roots with absolute ethyl alcohol. Alternately, the injection of absolute ethyl alcohol into the subarachnoid space may be employed.

All of these measures have been carried out on suitable subjects with good results in certain but not in all cases.

\section{Results of Bladder Training}

Let us now consider the degree of bladder control achieved as a consequence of this method of bladder training in female paraplegic patients.

The total number with whom we are concerned are divided into two groups, those with complete physiological transection of the cord or cauda equina, of whom there were 80,48 of these being of traumatic origin, and those with partial physiological transection of the cord or cauda equina, of whom there were I03, I 8 being 
due to trauma. These two groups were further subdivided in accordance with the type of bladder-i.e. spastic or flaccid.

We will first examine the results of bladder training in female paraplegics with complete transection of the spinal cord or cauda equina (table I).

\section{TABLE I}

80 Female Patients with Complete Cord Transection (Including 7 with urinary diversions)

\begin{tabular}{|c|c|c|c|c|c|c|c|c|c|c|}
\hline \multirow{2}{*}{$\begin{array}{l}\text { Method of } \\
\text { control }\end{array}$} & \multicolumn{3}{|c|}{ Type of bladder } & \multicolumn{3}{|c|}{ Voiding interval } & \multicolumn{4}{|c|}{ Residual urine } \\
\hline & Spastic & Flaccid & Unknown & $2-4 \mathrm{hr}$. & 3-5 hr. & Unknown & $\circ$ & $0-3 \circ \mathrm{ml}$. & $30-150 \mathrm{ml}$. & Unknown \\
\hline Cath & I 8 & 6 & 8 & - & - & - & - & - & - & - \\
\hline Good contr & 8 & ro & 14 & 4 & 23 & 5 & 5 & 13 & 6 & 8 \\
\hline $\begin{array}{l}\text { Fair control } \\
\text { Poor control }\end{array}$ & $\begin{array}{l}\mathrm{I} \\
-\end{array}$ & $\begin{array}{l}\mathrm{I} \\
\mathrm{I}\end{array}$ & $\begin{array}{l}4 \\
2\end{array}$ & ${ }^{2}-$ & ${ }_{-}^{\mathrm{I}}$ & $\begin{array}{l}3 \\
3\end{array}$ & $\begin{array}{l}- \\
-\end{array}$ & 2 & 2 & $\begin{array}{l}2 \\
3\end{array}$ \\
\hline
\end{tabular}

These were divided into two groups. The one with retaining catheter in the bladder, the other on bladder control without catheter. Also recorded is the type of bladder, frequency of voiding and residual.

In 80 patients with complete lesions, 32 were permantly dependent on urethral catheter drainage. This group of 32 comprised 18 with spastic bladders, 6 with flaccid bladders and 8 where bladder type could not be determined from the records. For the 32 remaining on catheter drainage, Table II indicates the factors enforcing reliance on this type of evacuation. In addition, a further 3 had permanent suprapubic catheters, 2 ilial bladders and 2 ureterostomies. Thus, 39 did not master bladder control.

\section{TABLE II}

\section{On Permanent Urethral Catheter Drainage}

(Complete Lesions)

\begin{tabular}{|c|c|c|c|c|c|}
\hline Under age ro. & . & . & - & . & \\
\hline Advanced carcinoma & & . & . & - & \\
\hline Unable to get on and off & toilet & . & . & . & \\
\hline Poor motivation & . & . & . & . & \\
\hline Left hospital too soon & . & . & . & - & \\
\hline Mentally retarded & . & . & . & . & \\
\hline Recurrent pressure sores & . & . & . & . & \\
\hline Back pain when straining & . & . & . & . & \\
\hline Poor abdominal muscles & . & . & . & . & \\
\hline Cystocele --Rectocele & . & . & . & . & \\
\hline Unknown $\quad$ : & & . $\quad$. & . & . & \\
\hline Control on discharge-re & verted & to catheter & & . & \\
\hline
\end{tabular}

Of the $4 \mathrm{I}$ who learned to void without a catheter (table I), 32 had good control, 6 fair and 3 poor control. Eight who gained good control had spastic bladders, Io had flaccid bladders and in I4 the bladder type was not recorded.

In evaluating bladder control, the frequency of bladder emptying and the amount of residual urine are the important considerations. Of the 32 with good 
control, 23 were able to void at intervals of 3 to 5 hours and remain dry. Four required to void at 2 to 4 hour intervals and for 5 there was no record. In this group the residual urine determination was as follows; zero for 5 , up to $30 \mathrm{ml}$. for $\mathrm{I} 3,30$ to $\mathrm{I} 50 \mathrm{ml}$. for 6 . The residual was not recorded in 8 cases.

Of the 6 cases with fair control, 2 required to void every 2 to 4 hours, I fell in the 3 to 5 hour group and for 3 there was no record. Not one of this group had a residual of zero, 2 were less than $30 \mathrm{ml}$., 2 from 30 to $150 \mathrm{ml}$. and for 2 there was no record. Three were classified as poor.

Bladder training in the I03 persons with partial lesions is a somewhat different problem and for the most part is more simple. Many of these patients possess a degree of sensory awareness which warns them that the bladder is full and they must void. This awareness may not be a normal sensory experience but in time the patient learns to recognise the warning even though it is abnormal in quality and is thus able to take steps to avoid incontinence. Likewise, the presence of complicating infection is recognised sooner as it causes discomfort which may lead to early treatment. Similarly, varying degrees of voluntary control of micturition is experienced by this group, some of whom have but minor impairment.

\section{TABLE III}

I03 Female Patients with Partial Cord Transection

(Including 2 with urinary diversions)

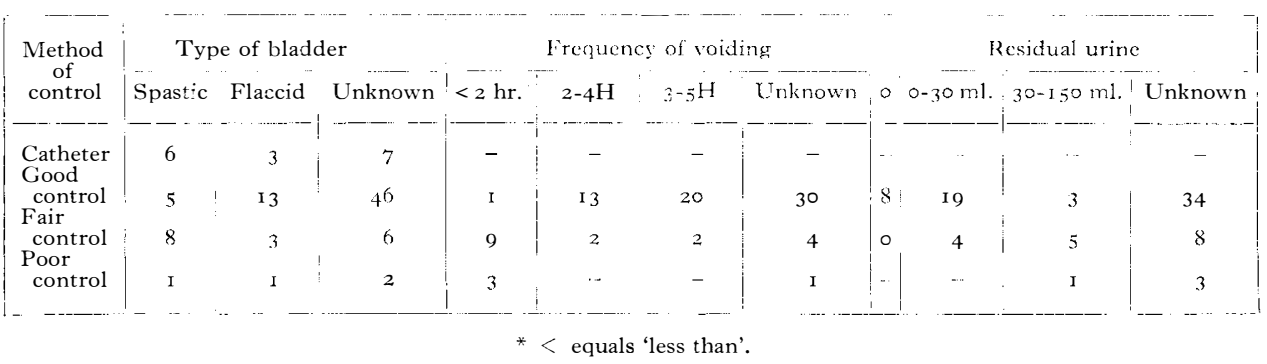

Of the 85 who did master bladder control (table III), 64 had good control, I 7 fair control and 4 poor control. Good control was effected by 5 with a spastic bladder, I3 with a flaccid bladder and in 46 the bladder type was not defined. The frequency of voiding was under 2 hours for I, every 2 to 4 hours for I3, 3 to 5 hours for 20 . No record was available for 30 patients, which may indicate that it was of little concern.

Eight had no residual and in 19 it was less than $30 \mathrm{ml}$. Three had a residual of from 30 to $\mathrm{I} 50 \mathrm{ml}$. and 34 did not have residual recorded in the chart.

Of the 17 with fair control, 8 had spastic bladders, 3 flaccid bladders, 6 were not recorded. Those with poor control were 4 in number-I spastic, I flaccid and 2 not recorded. The residual was high in I and not recorded in 3 .

Of I03 patients with partial lesions-I6 were compelled to rely on inlying urethral catheters. The reasons for this failure to eliminate the catheter are given in Table IV. Six of these had spastic bladders, 3 flaccid bladders and in 7 the record does not indicate the bladder type. One other had a permanent suprapubic catheter and one a sigmoid bladder. Thus, I 8 did not master bladder control. 


\section{DISCUSSION}

The arbitrary terms describing bladder control should be further defined. They are 'good', 'fair', and 'poor'.

Good control implies the ability to evacuate urine at regular intervals while remaining dry and achieving a low residual urine. Many such patients carry on for months without experiencing episodes of incontinence. The majority are dry during the full working day, on special social occasions and in bed. Urinary incontinence may, however, occur with extreme physical effort, cystitis or a distended lower bowel. The interval between voiding must be sufficient to permit of the patient pursuing necessary activities at work or play without being required to go to the toilet at frequent intervals.

Fair control is a lesser degree of continence, a shorter interval between voiding, a higher residual. Any one or all three may be present. Poor control implies a highly variable interval ending without warning-leading to much incontinence. Such a bladder precludes employment outside of the home and prevents social intercourse.

TABLE IV

On Permanent Urethral Catheter Drainage (inc. lesions)

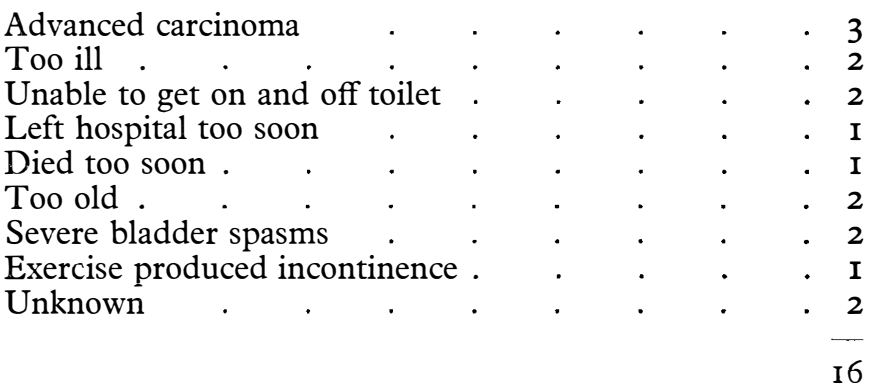

\section{CONCLUSION}

The essential points in bladder training are, a well-motivated patient who has a good concept of the purpose of the bladder training programme and who is willing to cooperate; a patient who has achieved reasonable agility at shifting herself about. The bladder should be of good capacity, free from acute infection and stones. The bowel must be well evacuated.

The patient and nurse should be prepared to persist in the training programme for weeks or months, using various approaches. One attempt per day, lasting two to four hours, is sufficient unless success is achieved. To prolong an unsuccessful effort is to induce fatigue and discouragement and may lead to sepsis. The approach is the same in principle whether the lesion be complete or partial, the bladder spastic or flaccid.

The degree of success is greater with partial than complete lesions for reasons already discussed. The long-term results of morbidity and survival have yet to be determined. However, it is of interest to observe the mortality figures thus far determined. Of the 80 patients with complete lesions, I4 are now dead, or 17.5 per cent.; of the I03 patients with partial lesions, I 2 are now dead, or I I 6 per cent. 
These figures are not too different from those compiled on a larger group of male and female paraplegics.

The methods described and results attained are the product of the experience of the nurses, orderlies, physicians and patients who have worked at Lyndhurst Lodge, Toronto, during the past 19 years.

\section{SUMMARY}

A programme of training for female paraplegics has been outlined which permits mastery of useful bladder control for half of 80 patients with complete transection of the spinal cord or cauda equina and for over 80 per cent. of 103 with partial lesions.

\section{RESUMÉ}

Un programme de rééducation vésicale pour les femmes paraplégiques est decrit, permettant la maitrise d'une fonction vésicale utile chez la moitié des 80 malades avec section complète de la moëlle épinière et de la queue de cheval, et, dans une proportion supérieure à $80 \%$ dans les lésions partielles.

\section{ZUSAMMENFASSUNG}

Die Autoren beschreiben ein Trainingsprogramm fuer querschnittsgelähmte Frauen, mit dessen Hilfe die Hälfte von 80 kompletten Läsionen des Rückenmarks und der Cauda equina ausreichende Blasenkontrolle erreichten. Bei I03 inkompletten Läsionen waren $80 \%$ der Patienten erfolgreich. 